\title{
ESBOÇO DE UMA TEORIA DA PONDERAÇÃO INDEPENDENTE DA TEORIA DOS PRINCÍPIOS
}

\author{
Marcelo Borges de MatTos Medina*
}

Poucas idéias têm exercido tanto fascínio sobre os teóricos do Direito contemporâneos quanto a da ponderação entre objetos colidentes. É admirável a atenção que a idéia em referência vem merecendo da academia, em especial nos últimos anos. Entretanto, não se trata de um tema exatamente novo. A ponderação, como técnica de solução de conflitos no âmbito do Direito, foi concebida ainda na passagem do século XIX para o século XX. Desde então, duas têm sido as constantes nas obras dos autores que se dedicam ao seu estudo: o gosto pela expressiva metáfora segundo a qual as colisões entre alguns objetos podem ser resolvidas mediante a atribuição de pesos diferentes a cada um deles, de modo a poder-se verificar qual possui maior importância; e a dúvida quanto à natureza dos objetos suscetíveis de ponderação. No início do século XX, consideravam-se ponderáveis os interesses envolvidos nas lides forenses. Mais tarde, passou-se a entender como ponderáveis os bens jurídicos ou os valores consagrados no ordenamento jurídico. Atualmente, prevalece o enteridimento de que a ponderação é a técnica própria para resolver as colisões entre os princípios de Direito. ${ }^{1}$

Talvez deva-se ao vínculo recentemente estabelecido entre a idéia de ponderação e a sedutora teoria dos princípios o incentivo para que tantos estudos devotem-se

* Mestrando em Direito Público pela Universidade do Estado do Rio de Janeiro.

1 Quanto às diferentes concepções formuladas pela jurisprudência dos interesses, pela jurisprudência dos valores e pela teoria dos princípios a respeito da natureza dos objetos suscetíveis de ponderação, v. Ricardo Lobo Torres, Da ponderação de interesses ao princípio da ponderação, in Urbano Zilles (coord.), Miguel Reale: Estudos em homenagem aos seus noventa anos. Porto Alegre: Edipuc-RS, 2000, p. 643 e ss. 
àquele assunto. Timbra festejada doutrina em acentuar a existência de duas espécies qualitativamente diferentes de normas jurídicas: os princípios, cujas colisões solucionar-se-iam por intermédio da técnica da ponderação; e as regras, cujos conflitos resolver-se-iam mediante o emprego dos critérios tradicionais de solução de antinomias (o hierárquico, o cronológico e o da especialidade). Assim, julgam os partidários de tais conceitos estar definitivamente afastada a incerteza acerca do objeto passível de sopesamento. Ledo engano. Quase tão rapidamente quanto se dissemina a teoria dos princípios, emergem sérios questionamentos em torno da possibilidade de uma distinção forte ou qualitativa entre as espécies de normas jurídicas. Nesse contexto, já começam a aparecer pesquisas que sugerem não seja a ponderação um método aplicável exclusivamente aos princípios. Ou, quem sabe, que talvez as regras sejam igualmente suscetíveis de ponderação...

O presente trabalho nasce ao influxo das preocupações do seu autor com semelhante estado de coisas. Aqui, todavia, não se vai encontrar mais uma opinião a respeito da natureza que hão de revestir os objetos ponderáveis. Outro é o caminho escolhido a fim de que uma tímida proposta para o impasse possa ser elaborada e submetida à crítica da comunidade jurídica. Quer parecer que a natureza dos objetos colidentes não seja aquilo que deva reclamar o emprego da ponderação. Antes, são os contornos do próprio conflito o que há de demandar a utilização de dita técnica ${ }^{2}$. É essa a tese esboçada nas páginas subsequientes, em um raciocínio construído em duas etapas. Em primeiro lugar, expõe-se uma suma da teoria dos princípios e das críticas que evidenciam o seu pouco préstimo para a teoria da ponderação. Depois, partindo-se do pressuposto de que tanto a ponderação quanto os critérios clássicos destinam-se a solucionar conflitos normativos, procura-se distinguir os casos aos quais se aplica cada um desses métodos.

2 Assim como já há quem afirme que as regras são suscetíveis de ponderação, também não faltam autores para defender a tese de que os princípios podem envolver-se em colisões somente solucionáveis pelos critérios tradicionais. Nessa linha, Luís Prieto Sanchís admite a hipótese de dois princípios - e.g. os princípios da igual dignidade humana e do apartheid - encontrarem-se em total antinomia, de modo que um deles deva ser considerado não pertencente ao ordenamento jurídico, certamente em razão da sua maior antiguidade ou menor hierarquia (Sobre principios y normas: problemas del razonamiento jurídico. Madrid: Centro de Estudios Constitucionales, 1992, p. 41). O próprio Robert Alexy, um dos mais conceituados teóricos dos princípios, vê-se ná contingência de reconhecer a existência de alguns princípios - como o da discriminação racial que, se aparecessem em um determinado ordenamento, haveriam de ser declarados inválidos em face de outros. Mas, a despeito disso, o autor mantém-se apegado à idéia de ponderação de princípios, aduzindo tão-somente que as colisões solucionáveis por tal método não são senão as ocorridas "dentro del ordenamiento jurídico" (Teoría de los derechos fundamentales, trad. de Ernesto Garzón Valdés. Madrid: Centro de Estudios Políticos y Constitucionales, 2001, p. 105). Ora, em sendo assim, parece de fato mais conveniente entender a ponderação como uma técnica aplicável a determinado tipo de conflito do que como um processo apto a resolver colisões entre normas de um determinado tipo. 
A teoria de que os princípios e as regras seriam espécies qualitativamente distintas de normas jurídicas foi pela primeira vez formulada por Ronald Dworkin, no final da década de 1960 . Valeu-se esse autor norte-americano de tal classificação particularmente para objetar a tese positivista de Herbert L. A. Hart, seu antecessor de cátedra na Universidade de Oxford, segundo a qual os casos difíceis ou controvertidos seriam resolvidos discricionariamente pelos juízes, com base nas suas preferências morais, sem a aplicação de norma jurídica alguma ${ }^{3}$. Dworkin rejeita vigorosamente semelhante entendimento. Para esse jurista, mesmo os chamados casos difíceis teriam solução correta, à luz do Direito. E, se Hart não pôde ver isso, foi por ser o seu conceito de Direito demasiadamente estreito.

Segundo o professor norte-americano, o modelo concebido por Hart tão-somente permitir-lhe-ia identificar as regras pertencentes a um ordenamento jurídico. Com efeito, sustenta Dworkin que o conceito positivista de uma norma-chave - como a regra de reconhecimento hartiana -, que permitiria submeter as outras normas a um teste de pertinência ou de pedigree, seria adequado apenas se o Direito fosse visto como um conjunto de regras, ao qual fossem estranhos os princípios ${ }^{4}$. E isso porque os princípios não se deixariam identificar por sua origem, mas por seu conteúdo e força argumentativa ${ }^{5}$.

Ora, prossegue Dworkin, se o conceito de Direito se esgotasse nesse conjunto de regras válidas e se alguma de tais regras não cobrisse claramente o caso a decidir - seja porque nenhuma parecesse apropriada, seja porque as que assim parecessem

3 A tese de Hart pode ser examinada na notável obra O conceito de Direito, trad. de A. Ribeiro Mendes, 3* edição. Lisboa: Fundação Calouste Gulbenkian, 2001, pp. 220 e 221, entre outras.

4 A norma de reconhecimento de Hart é imaginada como uma prática social geralmente aceita que estabelece quais são as normas juridicamente válidas. Trata-se de um conceito em alguns pontos próximo ao da norma fundamental de Kelsen. Ambos têm em comum, ao menos, a circunstância de servirem de critério para a identificação do que é Direito em dado lugar. Sobre a norma de reconhecimento de Hart, cf. ob. cit., p. 111 e ss.. A respeito da norma fundamental de Kelsen, v. Teoria Pura do Direito, trad. de João Baptista Machado, 4a edição. Coimbra: Armênio Amado. 1976, p. 277 e seguintes.

5 A crítica dirigida por Dworkin à norma de reconhecimento hartiana talvez seja um dos pontos da teoria daquele autor que suscite maiores dificuldades. É bem provável que Hart não tenha idealizado a sua norma-chave como um critério apto a identificar, também, os princípios de Direito. Mas, daí à conclusão de que norma de reconhecimento alguma permitiria a identificação dos princípios de um dado ordenamento jurídico vai uma grande distância. $\mathrm{Na}$ verdade, é bastante problemática a tese de que os princípios não se deixariam reconhecer por sua origem, mas apenas por seu conteúdo, como se se tratassem exclusivamente de um misterioso ponto de contato entre o Direito e os valores morais cultivados em certa sociedade. Eis a razão pela qual, neste estudo, não se leva em consideração a idéia de que os princípios não poderiam ser reconduzidos a um fundamento último de validade jurídica. Tal idéia, aliás, não é necessária nem mesmo para quem entenda possível uma distinção forte ou qualitativa entre princípios e regras (nesse sentido, Luís Prieto Sanchís, ob. cit., p. 83). De toda sorte, fica no texto o registro da opinião de Dworkin a respeito da matéria. 
fossem excessivamente vagas -, logo não seria de surpreender que não se pudesse julgar aplicando a lei. A solução, necessariamente, passaria pela discricionariedade judicial $^{6}$. Sucede, na verdade, que o Direito não seria composto somente por regras. Além dessas, haveria também os princípios. Ambas as espécies de normas seriam logicamente diferentes. Enquanto aquelas aplicar-se-iam conforme o esquema do tudo ou nada - o que significaria dizer que "si los hechos que estipula una norma están dados, entonces o bien la norma es válida, en cuyo caso la respuesta que da debe ser aceptada, o bien no lo es, y entonces no aporta nada a la decisión" 7 os princípios limitar-se-iam a enunciar razões de decidir, invocáveis em inúmeros casos. De tal modo, mesmo nos casos difíceis haveria normas aptas a ser empregadas pelos juízes, que assim poderiam quase sempre decidir segundo critérios jurídicos.

Os critérios jurídicos fornecidos pelos princípios, contudo, não seriam parecidos com aqueles relativos às regras. Os princípios - e aqui chega-se ao ponto importante para este estudo - possuiriam uma dimensão que faltaria a essas últimas: a dimensão do peso. Em consequiência, em caso de colisão entre dois princípios, a solução estaria em dar preferência ao que tivesse o maior peso relativo ${ }^{8}$. Nos casos difíceis, portanto, o intérprete deveria ir ponderando os princípios, a fim de decidir conforme aquele ao qual fosse atribuído o maior peso, sem que por isso o princípio preterido pudesse ser tido como alijado do ordenamento jurídico. Diferentemente, nas hipóteses de conflitos entre regras, outros procedimentos haveriam de ser levados a efeito. Como as regras não possuiriam a dimensão do peso, as antinomias entre elas encontrariam a sua superação exclusivamente nos critérios clássicos. De tal modo, ou uma das regras conflitantes poderia ser considerada especial em relação à outra ou uma delas teria necessariamente de ser tomada por inválida, em virtude do fato de ser mais antiga ou de ostentar menor hierarquia ${ }^{9}$.

O notável modelo desenvolvido por Dworkin calou fundo no meio acadêmico. E a distinção entre princípios e regras por esse autor reformulada acabou por influenciar os trabalhos a partir de então desenvolvidos em diversos âmbitos da teoria jurídica. Foi basicamente esse o modelo aproveitado, com alguns ajustes e complementações, pelo jurista germânico Robert Alexy, na construção de uma teoria dos direitos fundamentais tida como adequada para resolver os problemas centrais enfrentados na área: os problemas dos limites, das colisões e do papel representado pelos direitos fundamentais no sistema normativo ${ }^{10}$. O principal complemento acrescentado por Alexy à teoria de Dworkin consiste na conceituação dos princípios e das regras respectivamente como mandamentos de otimização e como mandamentos definitivos. Em outras palavras, os princípios seriam normas que determinariam fosse algo realizado no maior grau possível, segundo as possibilidades materiais e jurídicas existentes, enquanto as regras somente poderiam ser ou não cumpridas. Aí estaria,

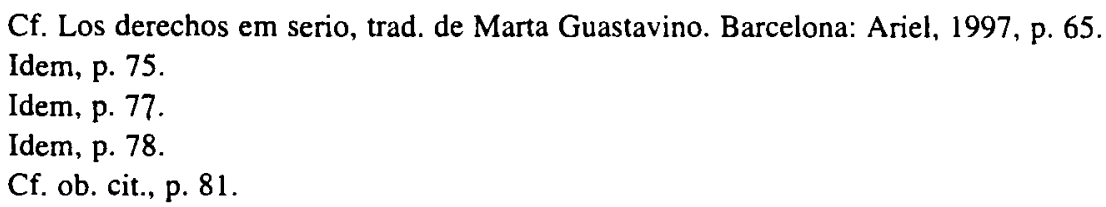


na visão do jurista europeu, o ponto decisivo para a distinção entre as duas espécies normativas, o qual explicaria de maneira mais precisa o seu comportamento nas hipóteses de antinomia ${ }^{1}$. Por ser mandamento de otimização é que um princípio poderia sobreviver a colisões, ainda quando houvesse de ceder passo para a aplicação de outro princípio, conforme as circunstâncias do caso concreto. De outra parte, em sendo as regras mandamentos definitivos, os conflitos entre normas de tal espécie não poderiam ser superados senão por meio de cláusulas de exceção ou pela declaração da invalidade de uma delas.

Os escritos de Alexy conduziram a teoria dos princípios a um patamar elevado de sofisticação. Ironicamente, porém, abriram um flanco por onde os opositores de uma distinção forte ou qualitativa das espécies normativas puderam tecer contundentes críticas. De um modo geral, consideram-se acertados os conceitos de mandamentos de otimização e de mandamentos definitivos. Ocorre que para muitos autores tais conceitos traduzem mais propriamente técnicas argumentativas aplicáveis a todas as normas do que uma suposta diferença de natureza entre princípios e regras. Bem vistas as coisas, segundo os aludidos juristas, não haveria diferentes espécies de normas a exigirem critérios diversos de solução de antinomias, mas apenas diferentes maneiras de manipular as normas na argumentação jurídica ${ }^{12}$.

$O$ fato de se pretender aplicar uma mesma norma às vezes como princípio, outras vezes como regra, parece efetivamente dar razão aos críticos. É significativo observar, a propósito, tenha sido o próprio Ronald Dworkin o primeiro a atentar para a dificuldade de a forma de um standard nem sempre deixar claro se é de um princípio ou de uma regra aquilo de que se trata. $O$ acatado professor norte-americano, tendo presente o exemplo oferecido pelo conteúdo da Primeira Emenda à Constituição de seu país, não deixou de observar poder ser motivo de controvérsia o modo pelo qual deve operar uma norma ${ }^{13}$. Ora, mas se a decisão por empregar uma norma como princípio ou como regra só pode ser tomada ao final de um processo de argumentação e de interpretação, então há de se concluir pela impossibilidade de uma distinção estrutural capaz de antecipar os respectivos critérios aplicáveis nos casos de colisão ou de conflito ${ }^{14}$.

11 Cf. ob. cit., pp. 86 e 87; El concepto y la validez del Derecho, trad. de Jorge M. Seña. Barcelona: Gedisa, 1994, p. 185.

12 Alexy, ciente das críticas dirigidas à sua formulação, viu-se constrangido a reconhecer só haver sentido em falar de mandamentos no sentido de que algo seja otimizado quando se tem em vista $o$ metanivel no qual se situam as técnicas argumentativas. Mas, nem por isso, achou de abrir mão da sua distinção entre princípios e regras. Ao revés, o autor limitou-se a reformular o conceito de princípios para considerá-los não como normas que determinam seja algo realizado na maior medida possível, mas como normas cujos conteúdos hão de ser realizados em semelhante grau (cf. On the structure of legal principles, in Ratio Juris, v. 13, n. 3, 2000, p. 300, onde Alexy traça a diferença entre commands to optimize e commands to be optimized).

13 Ob. cit., p. 78.

14 Não são poucas as manifestações doutrinárias no sentido de não ser possível dividir as normas entre as duas categorias propostas por Dworkin e Alexy, sem que antes tenham sido tais normas aplicadas. Para ficar só em alguns exemplos: nos Estados Unidos, Laurence H. Tribe não concorda 
Mas, será de fato impraticável distinguir aprioristicamente os princípios das regras, de modo a identificar os casos de ponderação e as hipóteses de antinomia a ser resolvidas pelos critérios clássicos? O exame da sofisticada versão elaborada por Robert Alexy para a teoria dos princípios não permite senão responder de maneira afirmativa a indagação. $O$ autor desenvolve a sua teve a fim de sustentar que

\section{(1) as normas são ponderáveis quando são princípios.}

Recorde-se que para Alexy, contudo, princípios seriam mandamentos de otimização, isto é, normas cujos conteúdos hão de realizar-se na maior medida possível, segundo as possibilidades fáticas e jurídicas existentes. Ora, ao afirmar que os princípios são mandamentos de otimização no que diz respeito às possibilidades jurídicas de seu cumprimento, não consegue o jurista significar outra coisa além de que princípios são as normas que se aplicam mediante ponderações que levem em conta as normas opostas ${ }^{15}$. Sucede que, em conseqüência, torna-se inevitável entender que

(2) as normas são princípios quando são ponderáveis ${ }^{16}$.

que "all constitutional provisions may be neatly classified at birth into one or the other of two distinct species, one reserved for broad and dynamic statements of abstract principle that are capable of elaboration and application only through the processes of moral philosophy, and the other reserved for dated, static, and concrete rules whose application does not engage the reader's moral faculties in any significant way" (Comment, in Antonin Scalia et alii, A matter of interpretation. Princeton: Princeton University Press, 1997, p. 69); na Europa, L. Gianformaggio, citada por Luís Prieto Sanchís, acredita que "la diferencia entre regla y principio surge exclusivamente en el momento de la interpretación-aplicación", de modo que dizer em abstrato se certa disposição contém uma regra ou um princípio "no tiene más significado que sugerir prácticas interpretativo. explicativas de un tipo más que de otro" (ob. cit., p. 53); no Brasil, Humberto Ávila acentua que "a atribuição do qualificativo princípios ou regras a determinadas espécies normativas depende, antes de tudo, de conexões axiológicas que não estão prontas antes do processo de interpretação que as desvela" (Teoria dos princípios: da definição à aplicação dos princípios jurídicos. São Paulo: Malheiros, 2003, p. 19).

15 Cf. Teoriạ de los derechos fundamentales, cit., pp. 86 e 112, especialmente.

16 Essa é uma conclusão autorizada pelo próprio Alexy, segundo o qual "quem empreende ponderação no âmbito jurídico pressupõe que as normas entre as quais se faz uma ponderação são dotadas da estrutura de princípios e quem classifica as normas como princípios acaba chegando ao processo de ponderação. A controvérsia em torno da teoria dos princípios apresenta-se, fundamentalmente, como uma controvérsia em torno da ponderação" (Conferência proferida na Fundação Casa de Rui Barbosa, Rio de Janeiro, em 10.12.1998, apud Gilmar Ferreira Mendes, Os direitos individuais e suas limitações: breves reflexões, in Gilmar Ferreira Mendes et alii, Hermenêutica Constitucional e direitos fundamentais. Brasília: Brasília Jurídica, 2000, p. 225).

Observe-se, para além das críticas feitas na sequiência do texto, que a sentença "as normas são princípios quando são ponderáveis" traduz uma noção muito pouco útil do que sejam os princípios. Afinal, se já não são as normas dessa espécie que reclamam o emprego da técnica da ponderação, mas a ponderação entre duas normas que justifica sejam essas chamadas de princípios, quase nada se ganha em chamá-las assim. É que a classificação das normas como princípios, nesse caso, não 
Todavia, assim nada se avança. E a teoria dos princípios, mesmo na sua versão mais bem formulada, acaba presa a um círculo tautologicamente vicioso. Ao pretender associar o conceito de princípios à técnica da ponderação, Alexy não logra nem bem delimitar aquele conceito nem bem prever os casos em que o emprego dessa técnica faz-se preciso. Em última análise, uma vez feito o possível intercâmbio entre os elementos das sentenças (1) e (2) acima destacadas, a teoria em apreço conduz às conclusões seguintes, de duvidosa utilidade:

(3) as normas são princípios quando são princípios;

(4) as normas são ponderáveis quando são ponderáveis.

Diante de tal quadro, não resta alternativa senão dissociar as teorias dedicadas ao estudo dos princípios e da técnica da ponderação. Alguns autores já vêm assim procedendo no que diz respeito ao estudo daquelas normas. Luís Prieto Sanchís, por exemplo, postula não seja o exame dos princípios vinculado ao esquema das antinomias ou contradições normativas. Esse autor, ciente das dificuldades inerentes a uma distinção ao estilo de Dworkin e Alexy entre as espécies de normas, prefere enxergar a singularidade dos princípios em uma dimensão funcional mais que estrutural. E, assim, entende ser possível preservar da inutilidade o conceito de princípios, de modo a não perder de vista a sua importância, "por ejemplo, en la resolución de lagunas, em la adjudicación de sentido a otras normas, etc." 17 . Convém, entretanto, não ficar tão-só no estudo da teoria dos princípios. Há, paralelamente, que isolar a ponderação como objeto de investigações independentes de uma distinção qualitativa entre as espécies normativas, a fim de determinar com precisão os casos em que aquela técnica deve ser empregada. Tal é o que se esforça por fazer, a partir de agora, este trabalho.

\section{III}

A tese exposta no item que se inicia postula que, à semelhança dos critérios hierárquico, cronológico e da especialidade, a ponderação há de ser empregada para solucionar algumas classes de antinomias normativas, para cuja caracterização afigura-se irrelevante a natureza das normas envolvidas. Nessa linha, sustenta-se a conveniência de reservar-se a utilização dessa última técnica para aquelas hipóteses

se prestará a esclarecer o modo pelo qual deverão ser aplicadas ou quando dever-se-á proceder à ponderação.

17 Ob. cit., pp. 54 e 55, para um breve exame dos propósitos que levam o autor a formular um conceito próprio de princípios. Entre nós, Humberto Ávila parece conceber novos pontos de vista para a distinção entre princípios e regras, ao influxo de considerações semelhantes. Para esse autor, "as distinções que separam os princípios das regras em virtude da estrutura e dos modos de aplicação e de colisão entendem como necessárias qualidades que são meramente contingentes nas referidas espécies normativas" (ob. cit., p. 16). 
em que os referidos critérios clássicos apresentam-se incapazes de indicar a norma segundo a qual a controvérsia há de ser decidida. Acredita-se que a ponderação, em tais hipóteses, encontrará campo propício para desenvolver as suas potencialidades ${ }^{18}$.

Os casos de antinomia variam conforme a extensão do conflito, a hierarquia e a antiguidade das normas envolvidas ${ }^{19}$. São três as possibilidades de antinomias, segundo a sua extensão. Em primeiro lugar, os pressupostos de fato das diferentes normas podem ser inteiramente coincidentes, de modo que ambas incidam sempre sobre as mesmas controvérsias, apontando, porém, para soluções divergentes. Em tais hipóteses, tem-se configurada a antinomia do tipo total-total. Exemplo de conflito desse jaez é o que ocorreria entre as normas (1) e (2) abaixo enunciadas:

(1) Na circunstância " A", deve ser " $X$ ".

(2) Na circunstância " $A$ ", não deve ser " $X "$.

Em segundo lugar, os pressupostos de fato de uma norma podem estar compreendidos nos pressupostos de fato de outra, de modo que numa mesma controvérsia possam ser devidas soluções distintas. Sendo esse o caso, ter-se-á presente uma antinomia do tipo total-parcial, na qual a primeira norma não será aplicada sem entrar em conflito com a segunda, embora a recíproca não seja necessariamente verdadeira. Tal conflito é o que se daria entre as normas (3) e (4), infra:

(3) Na circunstância "A", deve ser "Y".

(4) Nas circunstâncias "A" e "B", não deve ser " $Y$ ".

Por último, duas normas incompatíveis podem ter pressupostos de fato em parte coincidentes e em parte diferentes, de maneira que as controvérsias situadas no âmbito da interseção entre ambas devam ser resolvidas em sentidos opostos. Em

18 É importante ter sempre presente que os critérios hierárquico, cronológico e da especialidade não se aplicam por si mesmos, como se resultasse da própria natureza das coisas a solução das antinomias normativas conforme a orientação deles emanada. Trata-se de critérios convencionais, às vezes consagrados pelo Direito positivo, cuja aplicação somente se justifica quando demonstram aptidão para preservar a coerência do sistema jurídico. Daí se segue que, demonstrando a técnica da ponderação aptidão para resolver certas antinomias, tudo recomenda seja ela para tanto empregada.

19 Observe-se que as antinomias dão-se entre normas, não entre dispositivos legais. Conforme sublinha a moderna teoria jurídica, "normas não são textos nem o conjunto deles, mas os sentidos construídos a partir da interpretação sistemática de textos normativos. Daí se afirmar que os dispositivos se constituem no objeto da interpretação; e as normas, no seu resultado. O importante é que não existe correspondência entre norma e dispositivo, no sentido de que sempre que houver um dispositivo haverá uma norma, ou sempre que houver uma norma deverá haver um dispositivo que lhe sirva de suporte" (Humberto Ávila, ob. cit., p. 22). Bem poderá, portanto, uma norma à qual não corresponda um dispositivo - v.g., um princípio implícito, na visão dos adeptos da teoria dos princípios - envolver-se em uma das antinomias de que se cogita na sequência do texto. 
casos tais, ocorreriam antinomias do tipo parcial-parcial, tal qual a verificada entre as normas (5) e (6), em destaque:

(5) Nas circunstâncias "A" e " $B$ ", deve ser " $Z$ ".

(6) Nas circunstâncias " $B$ " e "C", não deve ser " $Z$ ".

Pois bem, combinados os três tipos de antinomia, segundo a sua extensão, com as diferentes possibilidades de relação entre normas de hierarquia e de antiguidade distintas, resultam 12 (doze) hipóteses de conflito entre normas jurídicas, a seguir elencadas:

(1) Conflito total-total entre normas de mesma hierarquia e antiguidade.

(2) Conflito total-total entre normas de mesma hierarquia e diferente antiguidade.

(3) Conflito total-total entre normas de diferente hierarquia e mesma antiguidade.

(4) Conflito total-total entre normas de diferente hierarquia e diferente antiguidade.

(5) Conflito total-parcial entre normas de mesma hierarquia e antiguidade.

(6) Conflito total-parcial entre normas de mesma hierarquia e diferente antiguidade.

(7) Conflito total-parcial entre normas de diferente hierarquia e mesma antiguidade.

(8) Conflito total-parcial entre normas de diferente hierarquia e diferente antiguidade.

(9) Conflito parcial-parcial entre normas de mesma hierarquia e antiguidade.

(10) Conflito parcial-parcial entre normas de mesma hierarquia e diferente antiguidade.

(11) Conflito parcial-parcial entre normas de diferente hierarquia e mesma antiguidade.

(12) Conflito parcial-parcial entre normas de diferente hierarquia e diferente antiguidade.

Cada critério tradicional de solução de antinomias aplica-se, convencionalmente, a algumas das hipóteses relacionadas. De sua parte, o critério hierárquico oferece resposta segura para os tipos de conflito de $\mathrm{n}^{\text {os }}(3),(4),(7),(8),(11)$ e (12). Conforme o critério em apreço, dentre duas normas incompatíveis, há de preferir-se a de superior hierarquia. Tal como dito na fórmula latina, lex superior derogat legi inferiori. Resulta esse critério da distribuição das normas jurídicas em escala hierárquica, de tal maneira que as normas inferiores devam encontrar nas superiores o imprescindível fundamento de validade. Daí se segue que aquelas não possam jamais ir de encontro a quanto nessas se estatui, sob pena de serem declaradas nulas. Pouco importa sejam as normas inferiores mais recentes ou mais específicas que as superiores. O interesse na preservação da ordem no sistema jurídico afasta a possibilidade 
de normas revestidas de menor hierarquia revogarem ou excepcionarem normas acima de si situadas ${ }^{20}$.

O critério cronológico aplica-se às hipóteses de antinomia de ${ }^{\text {os }}(2)$ e (10). Quer esse critério significar que a norma posterior prefere à anterior, sempre que essa última não tenha maior hierarquia nem seja especial em relação à primeira ${ }^{21}$. A essência do presente método traduz-se na expressiva máxima lex posterior derogat legi priori. Com efeito, é pela revogação da norma de maior antiguidade - isto é, pela cessação de sua vigência no ordenamento jurídico - que se resolvem os mencionados tipos de conflito. Mais precisamente, costuma-se dizer em vernáculo que é pela ab-rogação (revogação total) e pela derrogação (revogação parcial) que se solucionam, respectivamente, as hipóteses de $\mathrm{n}^{\text {os }}(2)$ e $(10)$.

20 O critério hierárquico tem primazia sobre todos os demais na solução dos conflitos normativos. Ensina Norberto Bobbio que o critério hierárquico prevalece tanto sobre o cronológico - "o que tem por efeito fazer eliminar a norma inferior, mesmo que posterior" - quanto sobre o critério da especialidade - visto que, e.g., "se se admitisse o princípio de que uma lei ordinária especial pode derrogar os princípios constitucionais, que são normas generalíssimas, os princípios fundamentais de um ordenamento jurídico seriam destinados a se esvaziar rapidamente de qualquer conteúdo". Assinala o autor, entretanto, que, se é bastante óbvia a supremacia do critério hierárquico sobre o cronológico, o mesmo não se pode dizer da prevalência daquele sobre o critério da especialidade. A maior dificuldade de solução, na última hipótese, deriva do fato de estarem em jogo "dois valores fundamentais de todo ordenamento jurídico, o do respeito da ordem, que exige o respeito da hierarquia e, portanto, do critério da superioridade, e o da justiça, que exige a adaptação gradual do Direito às necessidades sociais e, portanto, respeito do critério da especialidade" (Teoria do ordenamento jurídico, trad. de Maria Celeste Cordeiro Leite dos Santos, $4^{*}$ edição. Brasília: Ednunb, 1994, pp. 107 e ss.). Cumpre dizer, sem embargo, que ao menos no plano do Direito Constitucional já se prevêem instrumentos aptos a assegurar o devido respeito ao critério hierárquico, sem, contudo, conduzirem à nulidade da legislação ordinária especial. Tais instrumentos consistem nas técnicas de interpretação conforme a Constituição e de declaração parcial de inconstitucionalidade sem redução de texto, as quais permitem, dentro das possibilidades de significação do texto, a harmonização da norma inferior com o sentido emanado da norma superior. Sobre o tema, dentre muitos, v. Paulo Roberto de Gouvêa Medina, Direito Processual Constitucional. Rio de Janeiro: Forense, 2003, pp. 68 e 69; e Luís Roberto Barroso, Interpretação e aplicação da Constituição. São Paulo: Saraiva, 1996, p. 174 e seguintes.

21 Leciona Norberto Bobbio que, dos três critérios tradicionais, o cronológico é o mais fraco. Escreve o notável jusfilósofo que "esse princípio falha, não só quando a lex posterior é inferior, mas também quando é generalis (e a lex prior é specialis)", embora, quanto ao último ponto, considere o autor ser necessário "dispor de uma ampla casuística" para que se possa fazer afirmações mais precisas (ob. cit., p. 108). Na mesma linha, Francesco Ferrara manifesta dúvidas se, quando a uma lei especial se segue uma lei geral, "a nova regra não tolera mais os desvios e excepções da primeira ou quer mantê-las coordenando-as com o novo princípio" (Interpretação $e$ aplicação das leis, trad. de Manuel A. Domingues de Andrade, $2^{\mathbf{2}}$ edição. Coimbra: Armênio Amado, 1963. pp. 193 e 194). Como quer que seja, entre nós, o art. $2^{\circ}, \S 2^{\circ}$, do Decreto-Lei $n^{\circ}$ 4.657, de 4 de setembro de 1942 - a Lei de Introdução ao Código Civil - parece afastar eventuais incertezas acerca do conflito entre os critérios cronológico e da especialidade, ao consagrar a orientação de que "a lei nova, que estabeleça disposições gerais ou especiais a par das já existentes, não revoga nem modifica a lei anterior". 
O terceiro critério tradicional, o da especialidade, encontra nos tipos de conflito de $n^{o s}(5)$ e (6) a sua área de atuação. Duas normas entre as quais se dá um conflito do tipo total-parcial põem-se em uma relação de especial para com geral. De tal modo, sendo ambas de mesma hierarquia, a primeira há de prevalecer sobre a segunda, por força da máxima lex specialis derogat legi generali. Acentua Norberto Bobbio que a aplicação de semelhante critério deve-se a uma exigência de justiça, compreendida como tratamento igual de pessoas que pertencem à mesma categoria. Verificada a diferenciação entre duas categorias, "a persistência na regra geral importaria no tratamento igual de pessoas que pertencem a categorias diferentes, e, portanto, numa injustiça. Nesse processo de gradual especialização, operado através de leis especiais, encontramos uma das regras fundamentais de justiça, que é a do suum cuique tribuere (dar a cada um o que é seu). Entende-se, portanto, por que a lei especial deve prevalecer sobre a geral: ela representa um momento ineliminável do desenvolvimento de um ordenamento" 22 .

Nenhum dos critérios clássicos, contudo, oferece solução para as hipóteses de antinomia de $n^{\text {os }}$ (1) e (9). Não é para menos. Como a essa altura o leitor já terá observado, não há entre as normas em tais casos conflitantes qualquer diferença de hierarquia ou de antiguidade, nem tampouco uma relação de especialidade, que justificasse o emprego dos aludidos critérios ${ }^{23}$. Sem embargo, dir-se-á não residir nessa incerteza quanto aos métodos a adotar um problema que deva merecer maiores atenções do jurista preocupado com a prática do Direito. E isso porque as duas hipóteses de conflitos em referência, conquanto possíveis em tese, dificilmente verificar-se-iam na realidade. De fato, é pouco provável a ocorrência de um conflito do tipo (1) em ordenamentos jurídicos que guardem um mínimo de coerência entre os seus diversos elementos. Mas, ainda que a raridade de um fenômeno servisse de argumento contra o seu estudo, não se poderia perder de vista que os conflitos do tipo (9) chegam, na verdade, a ser freqüientes no corpo de um estatuto ou mesmo da Constituição. Especialmente nos catálogos de direitos fundamentais, pululam antinomias parcial-parcial entre normas de mesma hierarquia e antiguidade. É fácil imaginar um exemplo: a colisão entre a liberdade de imprensa e o direito à privacidade. Esquematicamente, assim pode-se dar a contradição entre as normas $\left(\mathrm{N}_{1}\right)$ e $\left(\mathrm{N}_{2}\right)$ correspondentes a cada um desses direitos:

$\left(\mathrm{N}_{1}\right)$ A divulgação de informações jornalísticas sobre fatos políticos, esportivos, relativos à vida das pessoas, etc. é permitida.

$\left(\mathrm{N}_{2}\right)$ A divulgação de informações jornalísticas sobre fatos relativos à vida das pessoas, a violação da correspondência, a escuta das comunicações telefônicas, etc. são proibidas ${ }^{24}$.

22 Ob. cit., p. 96.

23 Nesse sentido, Bobbio, ob. cit., pp. 97 e 98, onde esses dois tipos de antinomia são designados como insolúveis.

24 Não se pretende, na formulação das normas $\left(N_{1}\right)$ e $\left(N_{2}\right)$, esgotar os respectivos pressupostos de fato. Isso, certamente, não seria possível. Basta, contudo, exemplificar algumas das hipóteses de 
Evidentemente, é preciso formular critério apto a solucionar antinomias como a presente. A doutrina de alguns autores não ignora tal necessidade. Norberto Bobbio, debruçando-se sobre o tema, esforça-se por encontrar algum método satisfatório. Sucede que, ao final, o notável jusfilósofo não consegue mais que apontar como critério para a resolução dos conflitos do tipo (1) e (9) a absoluta falta de critérios. Resigna-se Bobbio em reconhecer que " no caso de um conflito no qual não se possa aplicar nenhum dos três critérios [clássicos], a solução do conflito é confiada à liberdade do intérprete". Em um caso dessa natureza, prossegue o autor, "poderíamos falar de um autêntico poder discricionário do intérprete, ao qual cabe resolver o conflito segundo a oportunidade, valendo-se de todas as técnicas hermenêuticas usadas pelos juristas por uma longa e consolidada tradição e não se limitando a aplicar uma só regra" 25 .

Mas, será que uma ampla discricionariedade quanto aos critérios a empregar apresenta-se realmente como a melhor solução para as hipóteses de antinomia em exame? Quer parecer que não. Imperativos de segurança jurídica e de controlabilidade das decisões judiciais estão a exigir a eleição de um critério certo para a resolução daqueles problemas. É aí que surge a técnica da ponderação como uma opção viável, por meio da qual poder-se-á superar os tipos de conflito de $n^{\text {os }}$ (1) e (9). Bastará, para tanto, determinar a qual das normas envolvidas há de ser conferido o maior peso, segundo as circunstâncias concretas da controvérsia. E, então, fazer incidir tal norma, em detrimento das demais ${ }^{26}$.

incidência de tais normas, para que se possa classificar a antinomia entre ambas existente no tipo de conflito de $n^{\circ}(9)$.

25 Ob. cit., p. 100. Na prática, observa Norberto Bobbio, a solução preferida pelos magistrados é a conservação das duas normas, pela demonstração de que não são incompativeis ou de que a incompatibilidade é apenas aparente, resultando de uma interpretação inadequada ou equivocada. Escreve o jurista italiano que "aquilo a que tende o intérprete comumente não é mais à eliminação das normas incompativeis, mas, preferentemente, à eliminação da incompatibilidade (sic)" (idem, p. 102). Assim, no entanto, não se resolve o problema. Ao revés, finge-se que ele não existe. A criativa atividade por meio da qual elimina-se o conflito pode, às vezes, ressentir-se de pouco apego àquilo que há de seguro no Direito positivo para a fundamentação das decisões judiciais. Se a interpretação, como ensinam as obras mais autorizadas, é sempre criativa, isso não significa possa ela ser arbitrária.

26 Não há incongruência alguma em rejeitar a idéia de que a ponderação destinar-se-ia a resolver as colisões de princípios e, ao mesmo tempo, continuar sustentando a tese de que tal técnica prestar-se-ia a fazer prevalecer a norma de maior peso relativo, no caso concreto. Mesmo para os partidários da teoria dos princípios, conforme sublinha Humberto Ávila, não é correto dizer que a dimensão de peso seja algo inerente a um dado tipo de norma. Nas palavras do autor, "não são, pois, os princípios que possuem uma dimensão de peso: às razões e aos fins aos quais eles fazem referência é que deve ser atribuida uma dimensão de importância" (ob. cit., p. 51). Tenha-se presente a circunstância de que as normas correspondem, invariavelmente, a razões para decidir num ou noutro sentido. E é entre tais razões que se há de fazer a ponderação. 
Acerca da proposta de adotar-se a ponderação como a técnica própria para a resolução dos conflitos dos tipos (1) e (9), pode-se, desde logo, apresentar um argumento favorável e um argumento contrário. A favor da proposta, cabe argumentar que a ponderação em tais termos concebida continuará a aplicar-se, de um modo geral, às incoerências entre normas cujos pressupostos de fato sejam mais vagos (e, portanto, mais suscetíveis de sobrepor-se parcialmente aos pressupostos de fato de outras normas), bem como às colisões entre direitos fundamentais. Mas, isso, sem que dita técnica deixe-se contaminar pelas dificuldades enfrentadas pela teoria dos princípios perfilhada pelos autores que defendem seja a ponderação empregada justamente para a resolução daquelas incoerências e dessas colisões ${ }^{27}$. De outra parte, é possível objetar à proposta ora formulada que a ponderação pouco contribuirá para restringir a discricionariedade com a qual o intérprete costuma resolver as hipóteses de antinomia consideradas insolúveis à luz dos critérios tradicionais. Com efeito, haverá sempre uma margem mais ou menos ampla para a determinação da norma à qual, em cada caso concreto, deverá ser atribuída a maior importância. Daí, contudo, não se segue acabem agindo com o mesmo grau de liberdade tanto o magistrado partidário da tese de que certas antinomias podem ser resolvidas discricionariamente quanto aquele que prefira a proposta da ponderação. No ponto, não se pode deixar de concordar com Robert Alexy. A circunstância de semelhante técnica não lograr conduzir a resultados certos e inequívocos não significa tratar-se de algo inútil. A técnica da ponderação, pelo menos, informa ao intérprete o que esse deve perguntar de modo a descobrir qual das normas há de ter a primazia, em um caso concreto ${ }^{28}$. $E$ isso basta para autorizar a sua adoção, na falta de alternativa mais segura.

27 É significativo que nos moldes da hipótese de antinomia parcial-parcial entre normas de mesma hierarquia e antiguidade encaixem-se tanto os exemplos de colisão entre princípios apresentados por autores como Dworkin e Alexy quanto aqueles casos que fazem a doutrina imaginar, não sem alguma perplexidade, a possibilidade de ponderação entre regras. Contra a proposta no texto formulada, contudo, um partidário da teoria dos princípios poderia, eventualmente, argumentar que as colisōes entre normas da espécie à qual deveria ser reservada aquela denominação não seriam classificáveis, segundo a maior ou menor sobreposição entre os seus pressupostos de fato, em total-total, total-parcial e parcial-parcial. Isso porque os princípios não possuiriam pressupostos de fato previamente determinados. Sucede que basta sejam as hipóteses de incidência de duas normas parcialmente determináveis no momento da aplicação para que a antinomia possa ser reduzida àquela classificação.

28 Cf. Teoría de los derechos fundamentales, cit., p. 164. Foge aos propósitos deste trabalho descrever, minuciosamente, o procedimento a ser seguido na ponderação entre normas antinômicas. Acerca do assunto, talvez fosse o caso de pensar em normas que, prima facie, ostentassem maior peso relativo e demandassem, por isso, uma maior carga argumentativa para que pudessem ser preteridas em caso de conflito. A tais normas, alguém poderia preferir designar como regras, em oposição a outras, de menor peso aparente, que seriam chamadas de princípios. É duvidoso, no entanto, que uma distinção assim formulada entre regras e princípios pudesse ainda ser caracterizada como forte ou qualitativa, à semelhança da classificação concebida por Dworkin e Alexy. Como quer que seja, na linha da proposta formulada no texto, a identificação das espécies normativas 
ALEXY, Robert. El concepto y la validez del Derecho, trad. de Jorge M. Seña. Barcelona: Gedisa, 1994.

. On the structure of legal principles, in Ratio Juris, v. 13, n. 3, 2000.

. Teoría de los derechos fundamentales, trad. de Ernesto Garzón Valdés. Madrid:

Centro de Estudios Políticos y Constitucionales, 2001.

ÁVILA, Humberto. Teoria dos princípios: da definição à aplicação dos princípios jurídicos. São Paulo: Malheiros, 2003.

BARROSO, Luís Roberto. Interpretação e aplicação da Constituição. São Paulo: Saraiva, 1996.

BOBBIO, Norberto. Teoria do ordenamento jurídico, trad. de Maria Celeste Cordeiro Leite dos Santos, $4^{\mathrm{a}}$ edição. Brasília: Ednunb, 1994.

DWORKIN, Ronald. Los derechos em serio, trad. de Marta Guastavino. Barcelona: Ariel, 1997.

FERRARA, Francesco. Interpretação e aplicação das leis, trad. de Manuel A. Domingues de Andrade, $2^{\text {a }}$ edição. Coimbra: Armênio Amado, 1963.

HART, Herbert L. A. O conceito de Direito, trad. de A. Ribeiro Mendes, $3^{\text {a }}$ edição. Lisboa: Fundação Calouste Gulbenkian, 2001.

KELSEN, Hans. Teoria pura do Direito, trad. de João Baptista Machado, $4^{\mathbf{a}}$ edição. Coimbra: Armênio Amado, 1976.

MEDINA, Paulo Roberto de Gouvêa. Direito Processual Constitucional. Rio de Janeiro: Forense, 2003.

MENDES, Gilmar Ferreira. Os direitos individuais e suas limitações: breves reflexões, in Gilmar Ferreira Mendes et alii, Hermenêutica Constitucional e direitos fundamentais. Brasília: Brasília Jurídica, 2000.

SANCHÍS, Luís Prieto. Sobre principios y normas: problemas del razonamiento jurídico. Madrid: Centro de Estudios Constitucionales, 1992.

TORRES, Ricardo Lobo. Da ponderação de interesses ao princípio da ponderação, in Urbano Zilles (coord.), Miguel Reale: Estudos em homenagem aos seus noventa anos. Porto Alegre: Edipuc-RS, 2000.

TRIBE, Laurence H.. Comment, in Antonin Scalia et alii, A matter of interpretation. Princeton: Princeton University Press, 1997.

envolvidas na antinomia seria útil tão-só para o desfecho da ponderação. No que diz respeito à escolha do método a ser aplicado para a solução do conflito - se o hierárquico, o cronológico, o da especialidade ou o da ponderação - a circunstância de as normas serem tomadas como regras ou como princípios seria absolutamente irrelevante. Aqui, continuaria a importar apenas os contornos da própria antinomia, para cuja configuração cóntinuariam a ser levados em conta somente a extensão do conflito, a hierarquia e a antiguidade das normas. 